\title{
PERANCANGAN FOSIL DIGITAL DINOSAURUS DENGAN PEMANFAATAN TEKNOLOGI HOLOBOX DI MUSEUM GEOLOGI BANDUNG
}

\author{
Abdul Haris Rustaman \\ Universitas Trilogi
}

\begin{tabular}{|c|c|c|}
\hline Received: 27 Januari 2018 & Revised: 08 Maret 2018 & Accepted: 15 Maret 2018 \\
\hline \multicolumn{3}{|c|}{ Available online at: bit.do/demandia }
\end{tabular}

\begin{abstract}
Abstrak: Museum Geologi Bandung merupakan salah satu museum terbesar di Indonesia yang banyak menyimpan fosil purbakala. Salah satu koleksi unggulan yang terkenal adalah replika fosil Dinosaurus Karnivora terbesar dan terganas yaitu Tyrannosaurusrex (Tyrex). Dinosaurus jenis ini merupakan objek yang menjadi primadona ketika mengunjungi Museum. Penerapan teknologi di Museum Geologi saat ini belum merata, informasi yang ditampilkan ketika mengujungi Dinosaurus disajikan masih bersifat statis berupa deskripsi teks, gambar dan fisik replika dari Tyrex. Hal ini belum dapat memberikan kesan visual yang dinamis dan interaktif. Pengumpulan data yang dilakukan pada penelitian ini berupa Observasi, Wawancara dan Studi Literatur. Diperlukan sebuah teknologi digital berupa Hologram Box (Holobox). Pemilihan teknologi Holobox karena penggunaan media digital sebagai media display saat ini semakin berkembang. Berdasarkan data rekapitulasi terakhir dari Museum Geologi Bandung jumlah pengunjung museum kategori terbanyak yaitu SMP sebesar 1.161.947 orang dan SMA sebesar 557.905 orang. Pengguna dari perancangan ini ditargetkan untuk pengunjung remaja usia 12 - 18 tahun (SMP dan SMA) yang sedang aktif mempelajari dan mencari informasi tentang fosil Dinosaurus. Hasil dari perancangan ini adalah multimedia interaktif Hologram $3 D$ (tiga dimensi) yang menampilkan informasi tentang Dinosaurus Tyrex secara dinamis.
\end{abstract}

Kata kunci: Fosil Digital, Dinosaurus, Holobox, Museum.

Abstract: Geology Museum of Bandung is one of the largest museums in Indonesia that preserves many ancient fossils. One of the best known collections is the fossilized replica of the largest and tallest carnivorous Dinosaur, Tyrannosaurus rex (Tyrex). This type of dinosaur is the object that becomes a preference at the Museum. The application of technology in the Geological Museum is currently imbalanced, the information displayed oh the Dinosaurs presented is still static in the form of text description, images and physical replicas of Tyrex. It has not been able to provide a dynamic and interactive visual impression. The data collected in this research are Observation, Interview and Literature Study. It takes a digital technology of Hologram Box (Holobox). The selection of Holobox technology is because of the use of digital media as a media display which is currently growing. Based on the latest recapitulation data from the Museum Geology Bandung, the

Penulis adalah pengajar pada Fakultas Industri Kreatif dan Telematika Program Studi Desain Komunikasi Visual Universitas Trilogi, email: aharisrustaman@trilogi.ac.id 
largest visitors of most categories of the museums are SMP students (1.161.947 people) and high school students $(557,905)$. The target audience is teenager $12-18$ year olds (junior and senior high school) who are actively studying and seeking information about dinosaur fossils. The result of this design is an interactive 3D Hologram (three-dimensional interactive) multimedia that dynamically displays information about Dinosaur Tyrex.

Keywords: Digital Fossil, Dinosaurs, Holobox, Museum.

\section{PENDAHULUAN}

Museum Geologi Bandung merupakan salah satu Museum Geologi terbesar di Indonesia yang banyak menyimpan fosil dan artefak sejarah. Berbagai koleksi geologi dan pertambangan terlengkap di Indonesia dapat dijumpai di Museum ini. Koleksi-koleksi unggulan tersebut antara lain fosil manusia purba Homo Erectus, fosil gajah purba Stegodontrigonocephalus, serta replika fosil Dinosaurus karnivora terbesar dan terganas Tyrannosaurusrex atau yang dikenal dengan Tyrex.

Data yang diperoleh dari wawancara dengan Bapak Danang selaku Humas di Museum Geologi bahwa dari sekian banyak fosil yang ada di Museum Geologi Bandung, objek yang paling diminati oleh pengunjung adalah jenis Dinosaurus Karnivor Tyrannosaurus rex. Hal ini dikarenakan bentuknya yang ganas dan buas. Diperkuat oleh survey yang dilakukan pada tanggal 19 Oktober 2014, dari ketiga fosil yaitu manusia purba, gajah purba dan Dinosaurus, sebanyak 54 responden/pengunjung diperoleh 69,23\% memilih fosil dinosaurus yang merupakan objek paling menarik perhatian.

Kepala Peragaan Musem Bapak Makmur, S.T, M.Hum menambahkan bawa pada penerapannya Museum Geologi Bandung terus berusaha mengembangkan inovasi yang dapat memberikandaya tertarik pengunjung terhadap konten pamer yang dimiliki. Diperlukan keterlibatan pihak-pihak yang sesuai dengan kebutuhan 
tersebut, peran seorang kurator, peneliti, engineer maupun designer sangat dibutuhkan dalam pengembangannya.

Penerapan teknologi di Museum Geologi Bandung belum sepenuhnya merata. Tata pamer koleksi fosil Tyrex pada lantai satu sayap barat museum penyajian kontennyamasih secara konvensional menggunakan media statis berupa gambar, bentuk dan data text. Keterbatasan informasi yang diperoleh pengunjung hanya mampu membayangkan peristiwa atau kejadian dengan cara menduga-duga. Oleh karenanya perlu dilakukan transformasi tata pamer fosil dengan memanfaatkan teknologi digital yang sedang berkembang saat ini.

Holobox merupakan salah satu media yang dianggap efektif sebagai alat display untuk menampilkan informasi dari fosil Dinosaurus secara dimensional. Pengunjung dapat melihat secara langsung gerak dan bentuk dari Dinosaurus tersebut dari empat sisi yaitu depan, belakang dan samping kiri kanan. Bentuk dari konten ini adalah Karakter $3 D$ berupa Video Animasi yang ditampilkan menggunakan limas kaca. Media ini dijalankan menggunakan Aplikasi Multimedia Interaktif yang diberi nama "HOXILUS" yaitu Hologram Box Fosil Dinosaurus. Berdasarkan uraian tersebut maka ditarik rumusan masalah berupa pertanyaan Bagaimana merancangan Fosil Konvensional menjadi Digital pada Dinosaurus dengan pemanfaatan Teknologi Holobox di Museum Geologi Bandung. Perancangan ini diharapkan dapat memberikan kemudahan bagi pengunjung untuk memperoleh pengetahuan tentang Dinosaurus melalui konten Dinosaurus Digital Hologram yang menarik dan dinamis.

\section{KAJIAN TEORI}

Holobox adalah gabungan dari dua kata yaitu hologram dan Box. Istilah "hologram" berasal dari kata Yunani untuk "keseluruhan" dan "tulis". Berbeda dengan foto biasa yang hanya merekam dua dari tiga dimensi dunia nyata, 
hologram bisa menampilkan obyek dalam rupa tiga dimensi (Krauss, 2003). Hologram sendiri terdiri atas Holografi yaitu suatu teknik perekaman gambar secara fotografi, yang memungkinkan dihasilkannya bayangan 3 dimensional. Dengan menggeser kedudukan mata, pengamat akan mendapat kesan melihat bayangan obyek dari berbagai segi (Shadily, 1982). Holografi adalah metode yang kita gunakan untuk merekam pola cahaya. Pola-pola ini direproduksi sebagai gambar tiga dimensi yang disebut hologram (Elmorshidy, 2010).

Perancangan ini akan menggunakan prinsip Multimedia Interaktif dan Realitas Virtual. Multimedia interaktif adalah suatu media yang dilengkapi dengan alat pengontrol yang dapat dioperasikan oleh pengguna, sehingga pengguna dapat memilih apa yang dikehendaki untuk proses selanjutnya.

Karakteristik dari multimedia interaktif adalah user tidak hanya memperhatikan media atau objek saja, melainkan juga dituntut untuk berinteraksi selama memperhatikan informasi dari media. Multimedia interaktif menggabungkan dan mensinergikan semua media yang terdiri dari teks, grafik, audio dan interaktivitas (Green \& Brown, 2002: 2-6).

Dalam perancangan media digital hologram fosil dinosaurus ini terdiri dari alat atau media pengontrol berupa user interface (antarmuka pengguna) merupakan aplikasi yang berfungsi sebagai perantara untuk dapat menjalankan media Holobox. Sebagai sebuah media interaktif maka dalam peracangan ini juga terdiri dari:

a. Teks, merupakan simbol berupa medium visual yang digunakan untuk menjelaskan bahasa lisan.

b. Grafik, adalah suatu medium berbasis visual. Seluruh gambar dua dimensi adalah grafik. Apabila gambar di render dalam bentuk tiga dimensi (3D), biasanya tetap disajikan melalui medium dua dimensi. 
c. Audio, medium berbasis suara adalah segala sesuatu yang bisa didengar dengan menggunakan indera pendengaran.

d. Interaktivitas, adalah rancangan dibalik suatu program multimedia, Interaktivitas dapat disebut juga sebagai interface design atau human factor design.

Sedangkan Realitas Virtual yaitu adanya ruang-ruang atau kondisi yang tidak bisa dicapai pada dunia nyata. Konsep dunia alternatif inilah yang menjadi daya tarik tersendiri akan hadirnya aplikasi maupun teknologi yang menghadirkan realitas virtual (Lefebvre, 1981).

Sebuah realitas virtual perkembangan kehidupan dinosaurus yang divisualisasikan melalui teknologi hologram, hal ini memungkinkan pengunjung dapat berimajinasi seolah karakter Dinosaurus hidup dan berada pada lingkungan nyata.

\section{METODE PENELITIAN}

Metode penelitian yang digunakan dalam perancangan ini menggunakan metode kualitatif. Pengumpulan data dilakukan dengan studi dokumen/teks, studi sejarah, observasi alami, serta wawancara terhadap narasumber. Aktivitas yang dilakukan pada tahap ini berupa pengamatan terhadap replika fosil Tyrannosaurusrex, wawancara dengan pegawai dan ahli fosil di museum untuk mendapatkan informasi terkait pengunjung museum, informasi tentang fosil dan dokumentasi dengan cara mengambil foto atau gambar serta koleksi-koleksi dokumen lain yang berhubungan dengan aset perancangan. Selanjutnya data dianalisis sebagai bahan dalam perancangan media untuk dijadikan rumusan dalam mengambil kesimpulan. 


\section{TARGET PENGGUNA}

Media Holobox Fosil Dinosaurus ini memiliki target pengguna yaitu Demografis usia primer dengan rata-rata usia 12-18 tahun. Media interaktif secara khusus membahas tentang fosil, materi ini diberikan kepada Pelajar/Siswa kelas SMP dan SMA, maka rentan usia pada masa tersebut berada pada 12 - 18 tahun. Hal ini disesuaikan dengan data kategori pengunjung Museum Geologi Tahun 2001 - Juni 2012 paling banyak berada di Pelajar SMP, dan berdasarkan data angket atau kuesioner, bahwa range usia tersebut adalah yang paling minat untuk melihat fosil dinosaurus yang ada di Museum Geologi Bandung. Sedangkan target sekundernya ditujukan untuk Wisatawan, baik orang dewasa maupun anak-anak guna menarik minat mereka untuk mempelajari fosil atau benda arkeolog yang ada di Museum Geologi Bandung. Sedangkan secara Psikografi perancangan media ini ditukan untuk semua pengunjung yang mampu menangkap pesan secara audio dan visual.

\section{HASIL DAN DISKUSI}

Bagian ini akan menguraikan analisisdata yang berkaitan dengan perancangan Holobox Fosil Dinosaurus baik dari wawancara, observasi maupun studi pustaka.

\section{Dinosaurus Cretacius sebagai Objek Penelitian}

Objek perancangan fosil Holobox ini dilakukan pada replika fosil dari Dinosaurus Karnivor Tyrannosaurus rex. Fosil ini merupakan fosil kerangka yang terbesar yang dapat dijumpai di Museum Geologi Bandung. Tyrannosaurus rex adalah dinosaurus yang hidup pada zaman kapur. Tyrannosaurus rex merupakan Dinosaurus pemakan daging terbesar dan terbuas yang paling terkenal; mempunyai kepala yang besar dengan gigi yang panjang dan tajam. 


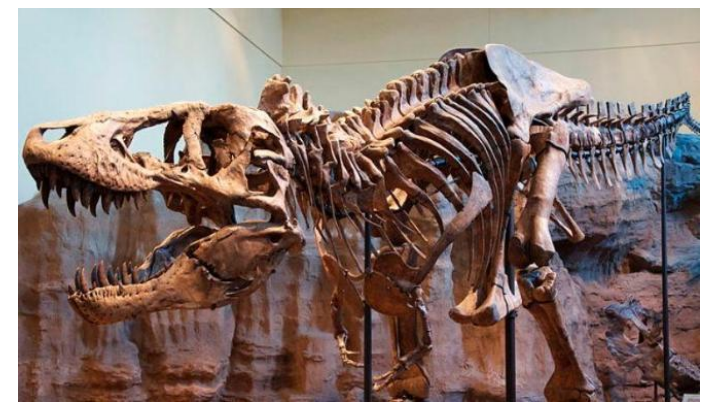

Gambar 1 Dinosaurus Karnivor Tyrannosaurusrex

Sumber: Rustaman, 2018

Adapun dinosaurus-dinosaurus lain yang hidup sezaman dengan Tyrex adalah Triceratops, Ankylosaurus, Pteranodon, Struthiomimus, Velociraptor dan Parasaurolophus. Sampel pembahasan perancangan difokuskan hanya pada Tyrex.

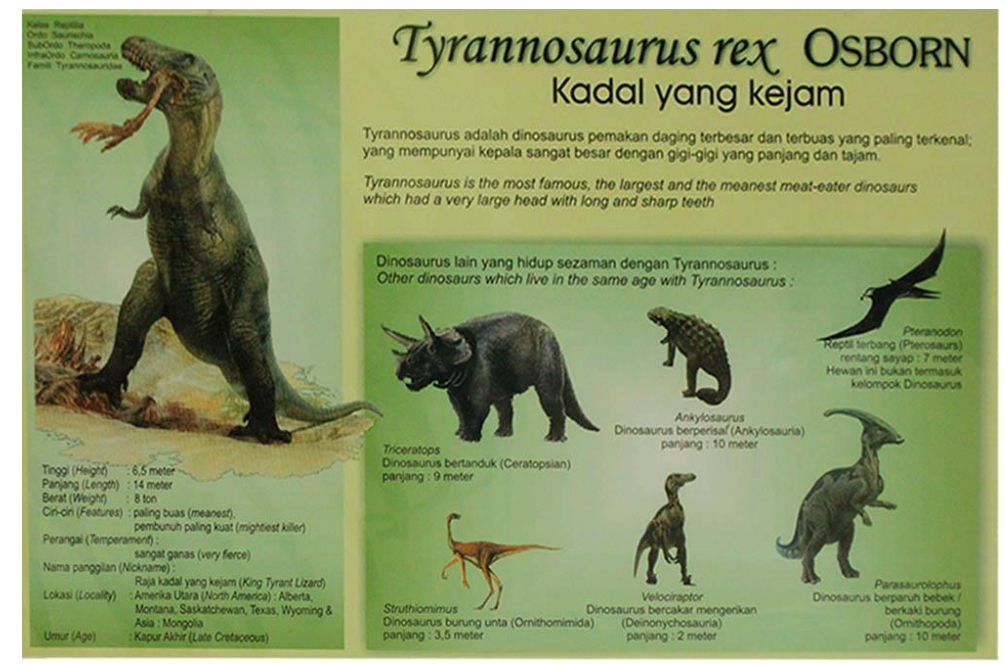

Gambar 2 Tyrannosaurusrex dan Dinosaurus yang hidup sezaman dengannya Sumber: Rustaman, 2018 


\section{Referensi Aplikasi Sejenis}

Tabel 1 Referensi Aplikasi Sejenis

Real Dinosaur Simulator merupakan aplikasi simulasi gambaran
kehidupan dari Tyrannosaurus rex. Didalamnya menampilkan
Tyrex ini menjadi penguasa pada masanya, menjadi predator
yang paling ganas untuk memburu mangsa. Adegan-adegan
yang ditampilkan dalam aplikasi ini adalah perilaku gigitan buas
dari Tyrex dengan gigi-giginya yang tajam. Perilaku lain yang
dapat kita lihat seperti ekspresi dari Tyrex yang mengejar
mangsa, dari sudut grafis aplikasi ini memanfaatkan $3 D$
sehingga lebih membuat objek terlihat nyata.

Dua aplikasi di atas berbasis smartphone dimana cara mengoperasikannya menggunakan touch screen, hal ini dapat dijadikan referensi dalam perancangan media Holobox Fosil Dinosaurus. Suara, Gerak, maupun aktivitas Dinosaurus yang ditampilkan pada aplikasi menjadi referensi dalam perancangan ini. Berikutnya interaksi yang dapat dilakukan oleh pengguna berupa menjalankan aplikasi HOXIILUS.

\section{Holobox sebagai Media Perancangan}

Holobox merupakan sebuah rancangan teknologi sederhana yang dibuat dengan menggabungkan screen monitor/tablet yang diletakan dan diproyeksikan di atas kotak kaca sehingga dapat menampilkan bayangan objek menyerupai hologram. Berikut ini adalah beberapa referensi terkait Hologram Box atau yang dikenal dengan Holobox. 

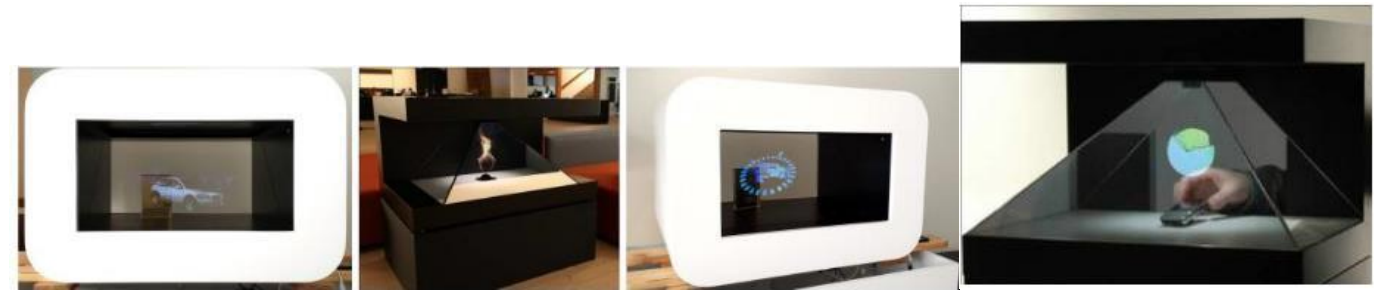

Gambar 3 Jenis-jenis Hologram

Sumber: http://247media.nl/de/products/Holobox/, akses 16 September 2014

Berdasarkan referensi tersebut, Holobox pada perancangan ini didesain dalam bentuk limas segi empat (piramida). Ukuran limas akan disesuiakan dengan kebutuhan besar dari layar (screen) $L C D$ yang akan ditampilkan.

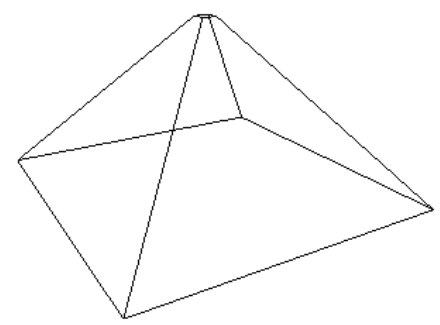

Gambar 4 Desain limas segi empat atau piramida kaca.

Sumber: Rustaman, 2018

Seperti gambar di atas, objek akan ditampilkan yaitu dari 4 sudut pandang, yaitu tampak depan, kiri dan kanan kaca atau limas.

\section{HASIL PERANCANGAN}

Dari referensi terkait yang telah dibahas sebelumnya, terciptalah Fosil HOXILUS (Hologram Box Fosil Dinosaurus). Dalam proses perancangannya diawali menyusun bagan cerita yang berisi gambar dan keterangan narasi/dubbing, musik/backsound dan durasi tampil. 
Tabel 2 Storyboard Informasi Dinosaurus Tyrex

\begin{tabular}{|c|c|c|}
\hline No. & Gambar & Keterangan \\
\hline \multicolumn{3}{|c|}{ Gambaran Kehidupan Tyrex } \\
\hline 1 & & $\begin{array}{l}\text { Narasi: Tyrannosaurus rex juga dikenal } \\
\text { dengan nama Tyrannosaurus atau Tyrex. } \\
\text { Nama Tyrannosaurus rex berasal dari Bahasa } \\
\text { Yunani, terdiri dari tiga bagian yaitu } \\
\text { "Tyranno" yang berarti tiran, "saurus" yang } \\
\text { berarti kadal, dan "rex" yang berarti raja. Jika } \\
\text { disambungkan maka akan menjadi Raja kadal } \\
\text { tiran. } \\
\text { Suara/musik: Adventure instrument } \\
\text { Durasi tampil: } 10 \text { detik }\end{array}$ \\
\hline 2 & & $\begin{array}{l}\text { Narasi: Tyrannosaurus adalah salah satu } \\
\text { dinosaurus pemakan daging terbesar yang } \\
\text { pernah hidup. Bayi Tyrex mendapatkan } \\
\text { makanan dari hasil buruan induknya. Sejak } \\
\text { bayi Tyrex sudah diajarkan memakan daging. } \\
\text { Namun pada masa anak-anak mereka belum } \\
\text { diajarkan bagaimana cara memburu mangsa. } \\
\text { Suara/musik: Adventure instrument } \\
\text { Durasi tampil: } 25 \text { detik }\end{array}$ \\
\hline 3 & & $\begin{array}{l}\text { Narasi: Tyrex dapat melindungi diri dari } \\
\text { musuh dengan memanfaatkan kekuatan yang } \\
\text { ada di kepala dan ekornya. Tyrex juga } \\
\text { memiliki kepala yang besar dan rahan yang } \\
\text { kuat, hal ini digunakan untuk menerkam } \\
\text { musuh. } \\
\text { Suara/musik: Adventure instrument } \\
\text { Durasi tampil: } 30 \text { detik }\end{array}$ \\
\hline 4 & & $\begin{array}{l}\text { Narasi: Terdapat } 2 \text { teori penyebab } \\
\text { kepunahan Tyrannosaurus rex. Teori pertama } \\
\text { mangatakan adanya pemanasan global dan } \\
\text { kenaikan permukaan air laut. } \\
\text { Teori kedua menyebutkan karena jatuhnya } \\
\text { meteor di Semenanjung Yucatan, di kawasan } \\
\text { tenggara Meksiko. Meteor ini menyebabkan } \\
\text { kebakaran raksasa, melontarkan serpihan } \\
\text { debu ke langit dan memblokir sinar matahari } \\
\text { selama ratusan juta tahun. } \\
\text { Suara/musik: Adventure instrument } \\
\text { Durasi tampil : } 30 \text { detik }\end{array}$ \\
\hline \multicolumn{3}{|c|}{ Ciri-ciri DinosaurusTyrex } \\
\hline 5 & & $\begin{array}{l}\text { Narasi: Secara fisik Dinosaurus ini memiliki } \\
\text { ciri-ciri, Kepala yang besar dan ekor yang } \\
\text { kaku, hal ini berfungsi sebagai penyeimbang } \\
\text { ketika berjalan agar lebih lincah. } \\
\text { Suara/musik: Adventure instrument } \\
\text { Durasi tampil: } 20 \text { detik }\end{array}$ \\
\hline
\end{tabular}




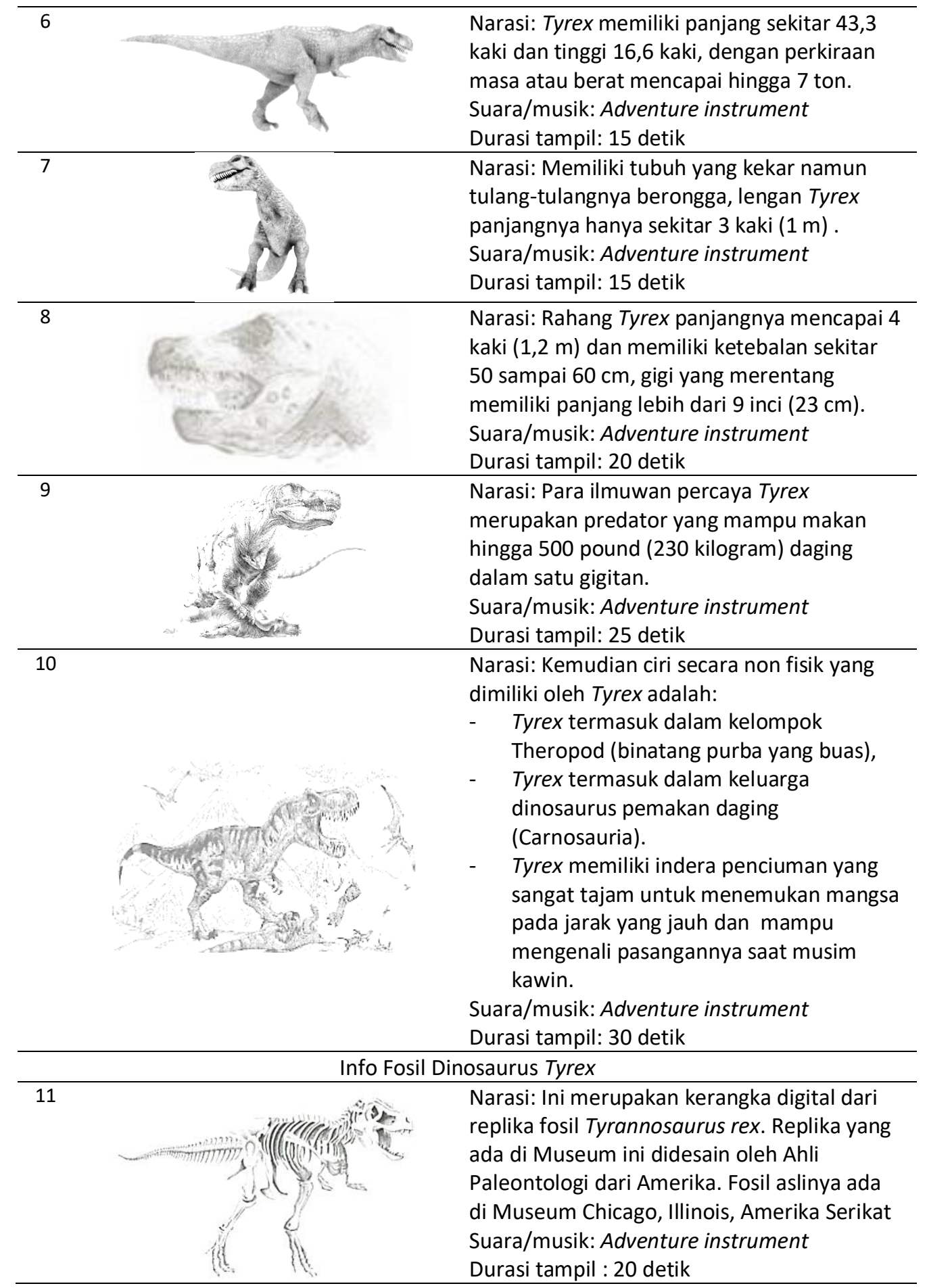




\begin{tabular}{|c|c|}
\hline 12 & $\begin{array}{l}\text { Narasi: Beberapa bagian dari fosil Dinosaurus } \\
\text { yang ada di Museum yaitu seperti cetakan } \\
\text { kaki Tyrex. Cetakan kaki ini ditemukan oleh } \\
\text { ahli paleontologi Inggris yang bernama Phil } \\
\text { Manning, pada tahun } 2007 \text { di Hell Creek } \\
\text { Formation, Montana (negara bagian } \\
\text { Amerika, berbatasan dengan Kanada). } \\
\text { Suara/musik: Adventure instrument } \\
\text { Durasi tampil: } 30 \text { detik }\end{array}$ \\
\hline 13 & $\begin{array}{l}\text { Narasi: Tyrex memiliki gigi yang berbentuk } \\
\text { runcing bergerigi tajam, panjang giginya } \\
\text { mencapai } 20 \mathrm{~cm} \text {. Tyrex memiliki gigi yang } \\
\text { banyak. Gigi-gigi ini memang sudah ada sejak } \\
\text { Tyrex masih kecil. Gigi yang tajam ini } \\
\text { berfungsi untuk merobek daging dan } \\
\text { menghancurkan tulang-tulang mangsanya, } \\
\text { gigi-gigi ini juga berfungsi untuk memberi } \\
\text { makan anak-anaknya. } \\
\text { Suara/musik: Adventure instrument } \\
\text { Durasi tampil : } 30 \text { detik }\end{array}$ \\
\hline 14 & $\begin{array}{l}\text { Narasi: Lengan Tyrannosaurus relatif sangat } \\
\text { kecil untuk ukuran tubuh secara keseluruhan, } \\
\text { ukuran lengannya hanya } 1 \text { meter (3,3 kaki). } \\
\text { Lengan ini memiliki jangkauan gerak yang } \\
\text { terbatas yaitu sekitar } 40 \text { sampai } 45 \text { derajat } \\
\text { dari sisi bahu dan siku. } \\
\text { Suara/musik: Adventure instrument } \\
\text { Durasi tampil : } 30 \text { detik }\end{array}$ \\
\hline 15 & $\begin{array}{l}\text { Narasi: Ini merupakan Ruas tulang belakang } \\
\text { Tyrex. } \\
\text { Suara/musik: Adventure instrument } \\
\text { Durasi tampil : } 10 \text { detik }\end{array}$ \\
\hline
\end{tabular}

Berikutnya adalah digitalisasi karakter Tyrex dari referensi terkait dengan melakukan sketsa karakter dari tampak samping, depan dan belakang. Selanjutnya modelling 3D menggunakan Software Blender. Memberi warna/texture kulit, penulangan untuk pergerakannya/animate dan rendering untuk menghasilkan sebuah animasi yang utuh. Dalam sebuah scene dilakukan 4 kali render yaitu render tampak depan, belakang samping kiri dan kanan sehingga dapat diproyeksikan pada setiap sisi limas kaca. Selanjutnya yaitu pemberian suara. Suara yang diaplikasikan yaitu suara musik pada trailler, narasi prolog, suara latar (backsound), dan suara Dinosaurus pada saat mengaung, saat berkelahi, saat 
makan dan suara jatuhnya meteor saat cerita punahnya dinosaurus dan sebagainya, bahkan suara pada tombol interface-menu. Tema musik yang digunakan yaitu Adventure, strain, klasik purba, dan nature. Berikutnya membuat dubbing atau rekaman suara untuk narasi, hasil dari rekaman suara ini berupa format ".wav" atau ".mp3". Aplikasi yang digunakan adalah Sound recorder.

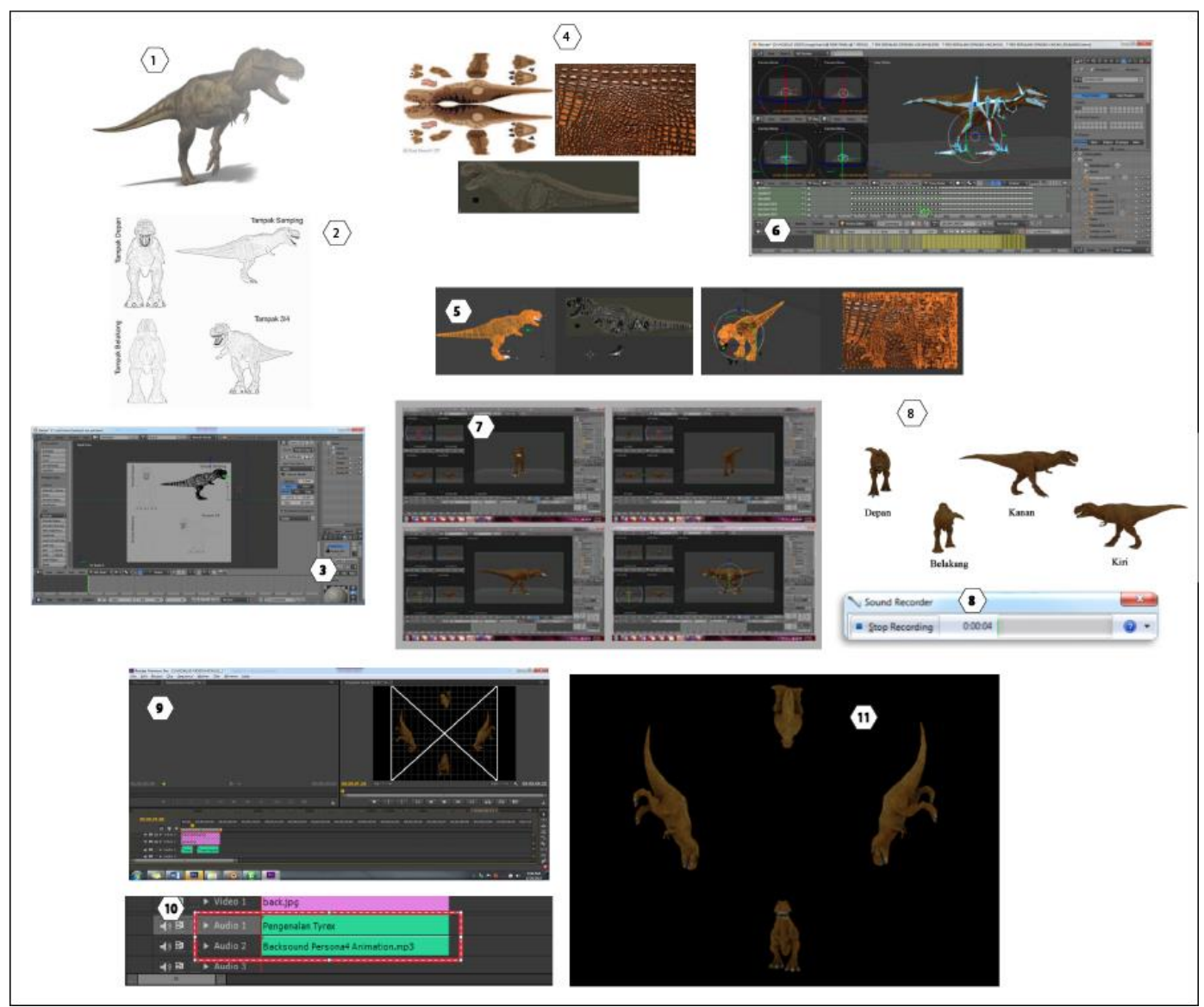

Gambar 5 Desain limas segi empat atau piramida kaca Sumber: Rustaman, 2018

Selanjutnya yaitu perancangan user interface atau antarmuka pengguna, berfungsi sebagai aplikasi untuk mengontrol jalannya Hologram Dinosaurus. Menu aplikasi terdiri dari Dinosaurus yang hidup pada masa Cretacius/Kapur. Beberapa bagian menu dikunci untuk pengembangan ke depan. Dalam sampel ini konten hologram difokuskan pada Tyrannosaurus rex/Tyrex. Informasi yang ditampilkan 
pada media yaitu tentang gambaran kehidupan dinosaurus, ciri-ciri dinosaurus dan informasi tentang replika fosil dinosaurus. Nama yang digunakan pada media interaktif adalah "HOXILUS" yaitu "Hologram Fosil Dinosaurus".

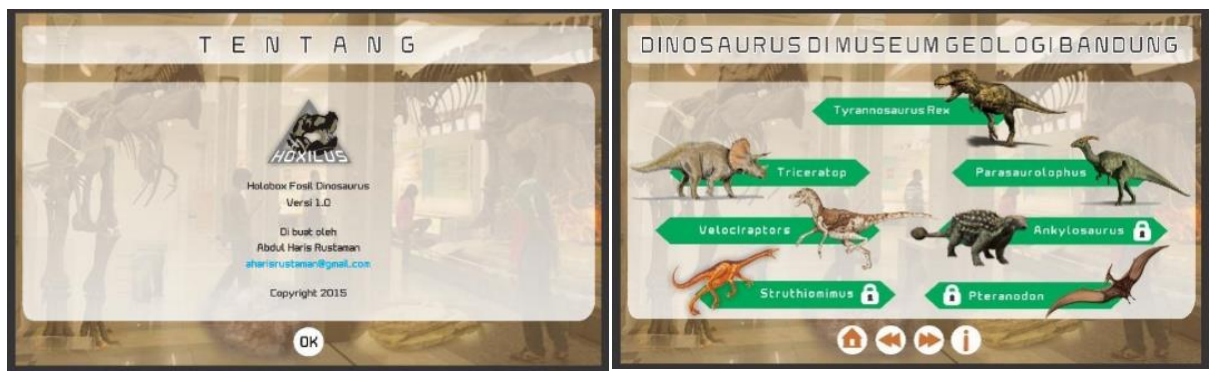

Gambar 6 User interface "Info Aplikasi dan Menu Aplikasi"

Sumber: Rustaman, 2018

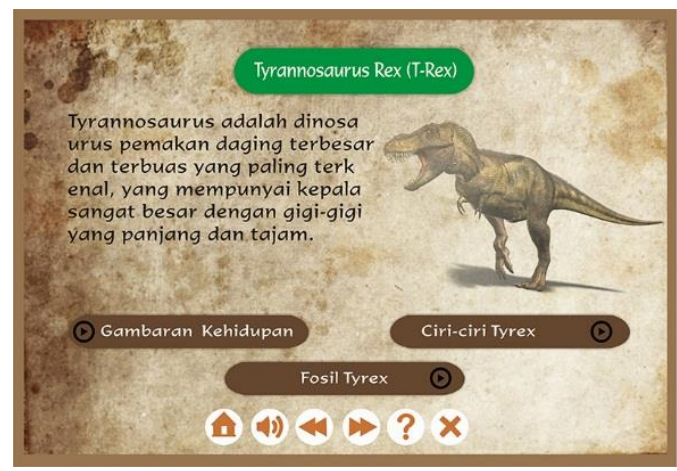

Gambar 7 User interface “HOXILUS” (Hologram Fosil Dinosaurus)

Sumber: Rustaman, 2018

Berikutnya adalah penggabungan media menjadi sebuah multimedia interaktif. Tiga kompenen utama untuk menjalankan HOXILUS yaitu User (Pengunjung) berfungsi untuk mengontrol dan menjalankan aplikasi. Desktop pada keterangan gambar nomor 7 yaitu media untuk menampilkan aplikasi HOXILUS, desktop dengan layar sentuh memudahkan user memilih info Dinosaurus yang ditampilkan. Media Holobox, merupakan perangkat untuk menampilkan hologram fosil dinosurus. 


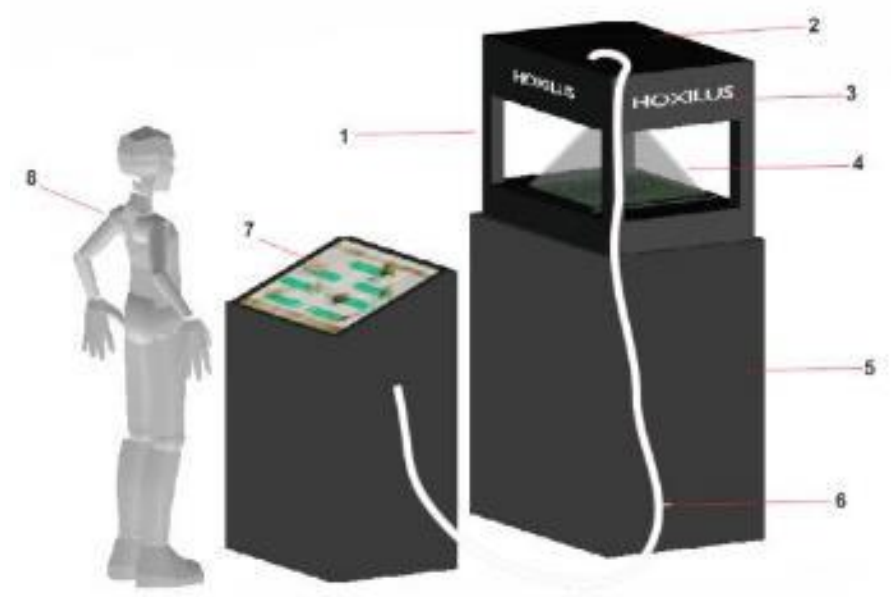

Gambar 8 Penggabungan Rancangan Media Holobox

Sumber: Rustaman, 2018

(1) Rangka casing (2) Monitor LCD (3) Label HOXILUS (4) Kaca Piramida media Holobox (5) Penutup Kali Media (6) Kabel HDMI (7) Aplikasi HOXILUS (8) User/Pengunjung.

Berikutnya adalah merancangan limas/piramida kaca yang digunakan untuk memvisualisasikan konten fosil dan dinosaurus.
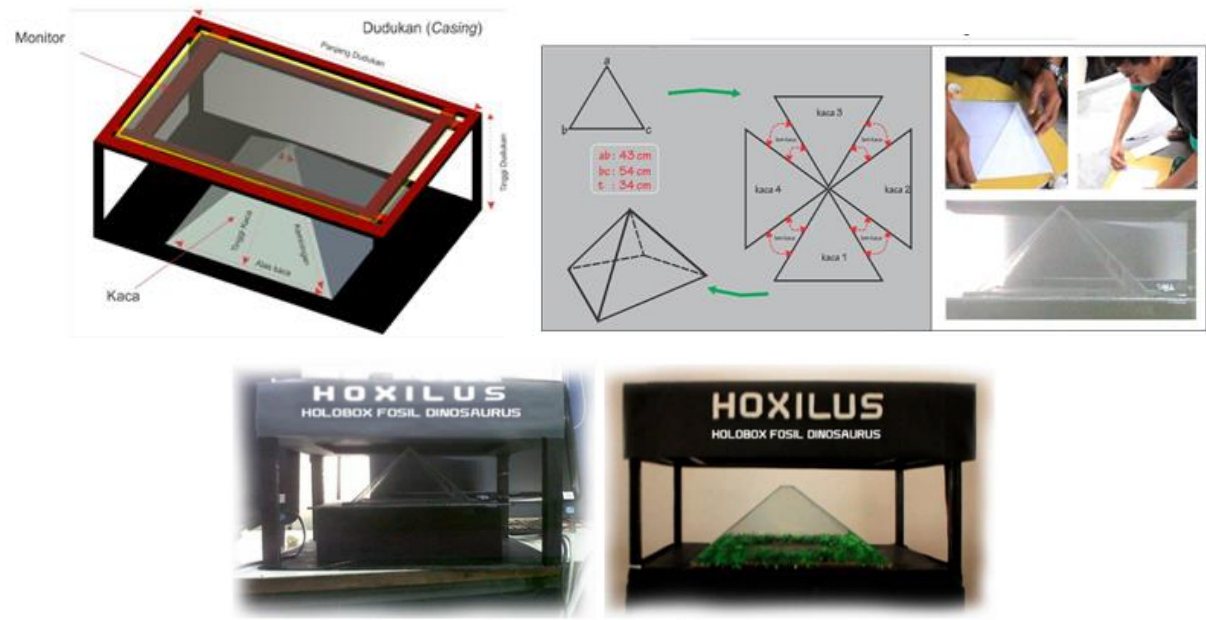

Gambar 9 Holobox Ukuran 15" dan 32"

Sumber: Rustaman, 2018

Dudukan ini merupakan media sebagai tempat untuk menyimpan piramida kaca dan penyangga monitor. Ukurannya disesuaikan dengan tinggi serta panjang dan lebar dari piramida dan monitor. Desain yang ada pada kepala 
dudukan terdapat tulisan "HOLOBOX FOSIL DINOSAURUS". Warna yang diberikan untuk desain dudukan ini adalah hitam dengan dua tujuan yaitu fokus proyeksi objek dan fokus dari pandangan penglihatan pengguna. Karena konten-konten yang akan ditampilkan pada media Holobox dengan pewarnaan full kecuali background yang disetting transparan sehingga memperoleh display objek yang baik.

Dengan dua dampak yang pertama efek dari kotak, akan memberikan pantulan cahaya terhadap objek yang divisualisasikan ke dalam media piramida kaca. Efek yang kedua, pada sisi user atau pengguna dimana user akan melihat konten yang divisualisasikan dengan desain yang nyaman, rapi, dan kotak tersebut telah didesain untuk menjaga piramida kaca agar lebih aman dari segala gangguan kemungkinan yang akan terjadi.

Dalam peracangan ini, dilakukan dua tahap yaitu membuat rancangan prototype dengan media menggunakan monitor 15 inc dan 32 inc. Pada percobaan awal menggunakan media yang lebih kecil objek yang dihasilkan juga keci, demikian juga menggunakan media dengan layar yang lebih besar maka proyeksi objek yang di hasilkan dari kaca akan semakin besar.

Tabel 3 Perbandingan Ukuran Media Holobox

\begin{tabular}{|c|c|c|c|c|c|}
\hline \multirow[t]{2}{*}{ Monitor } & \multicolumn{2}{|c|}{$\begin{array}{c}\text { Ukuran Kaca } \\
\text { Dudukan/Casing }\end{array}$} & \multicolumn{2}{|c|}{ Dudukan/Casing } & $\begin{array}{l}\text { Jarak Monitor } \\
\text { ke Ujung Limas }\end{array}$ \\
\hline & Tinggi & $: 14,5 \mathrm{~cm}$ & Tinggi & $: 24,5 \mathrm{~cm}$ & \multirow{3}{*}{$1 \mathrm{~cm}$} \\
\hline \multirow[t]{2}{*}{$15^{\prime \prime}$} & Alas & $: 20,5 \mathrm{~cm}$ & Panjang & $: 37 \mathrm{~cm}$ & \\
\hline & Sisi Miring & $: 17,5 \mathrm{~cm}$ & Lebar & $: 24 \mathrm{~cm}$ & \\
\hline \multirow{3}{*}{$32 "$} & Tinggi & $: 14,5 \mathrm{~cm}$ & Tinggi & $: 24,5 \mathrm{~cm}$ & \multirow{3}{*}{$3 \mathrm{~cm}$} \\
\hline & Alas & $: 20,5 \mathrm{~cm}$ & Panjang & $: 37 \mathrm{~cm}$ & \\
\hline & Sisi Miring & $: 17,5 \mathrm{~cm}$ & Lebar & $: 24 \mathrm{~cm}$ & \\
\hline
\end{tabular}

Tahap selanjutnya adalah uji coba perangkat dengan rangkain proses yaitu melakukan pemasangan media Holobox menggunakan monitor 32" dengan tujuan 
untuk mendapatkan proyeksi konten yang lebih besar. Rangkain proses ini terdiri dari (1) merangkai dudukan kaca piramida dan monitor, (2) meletakkan kaca dalam dudukan, (3) meletakkan monitor, (4) memasang kabel hdmi pada monitor, (5) menutup dudukan kepala monitor, (6) menyiapkan laptop/PC, (7) mengatur extend pada windows, (8) Menjalankan aplikasi HOXILUS, (9) Memilih konten yang akan ditampilkan pada media Holobox, (10) Melihat hasilnya pada kaca piramida.
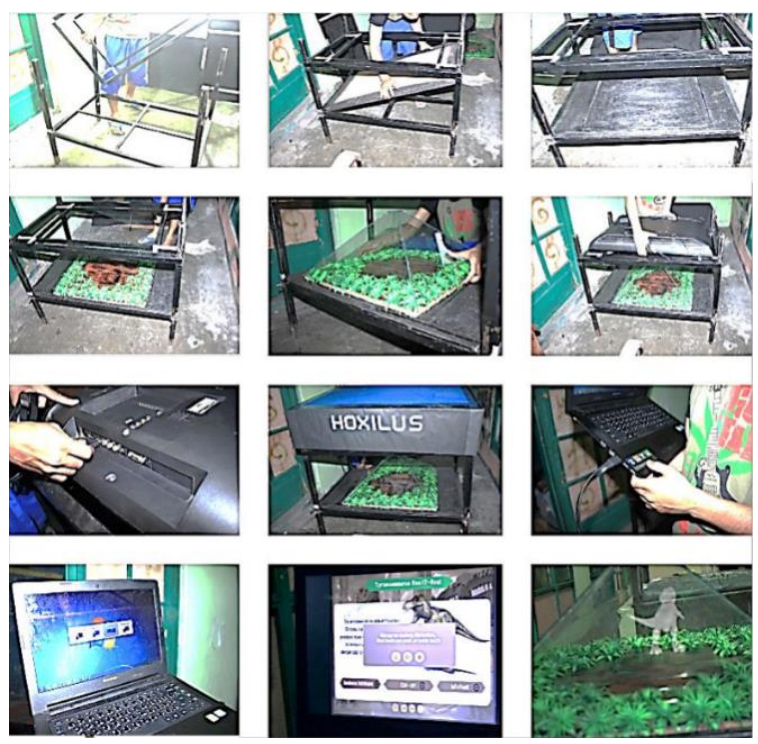

Gambar 10 Rangkaian Proses Pemasangan Holobox Sumber: Rustaman, 2018
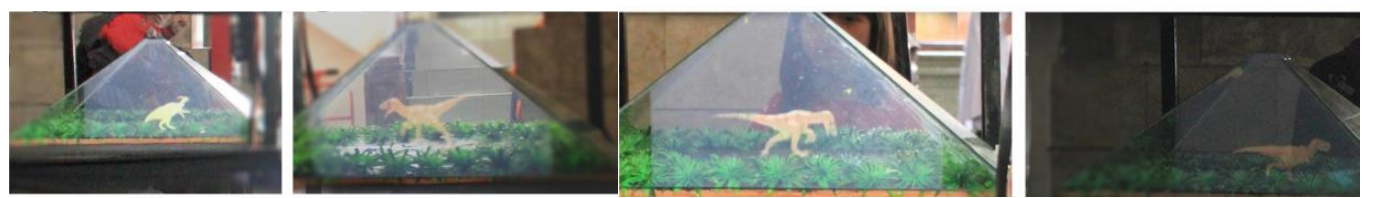

Gambar 11 Rangkaian Proses Pemasangan Holobox Sumber: Rustaman, 2018

Rangkaian proses pemasangan sudah dilakukan selanjutnya adalah post test Media Perancangan di Museum Geologi untuk mendapatkan respon dari pengunjung. Post Test pertama pada tanggal 24 dan 25 Mei 2015. HOXILUS ditempatkan pada indoor yaitu loby utama Museum Geologi Bandung. Hasil post test diperoleh bahwa $100 \%$ pengunjung mengatakan setuju apabila media 
tersebut diterapkan di Museum Geologi Bandung, dan media tersebut sangat membantu remaja SMP dan SMA khususnya dan semua pengunjung umumnya untuk memperoleh informasi tentang dinosaurus serta $90 \%$ dari pengunjung mengatakan bahwa HOXILUS mampu memberikan informasi secara detail dari gambaran kehidupan, ciri-ciri, dan informasi tentang fosil Tyrannosaurus rex yang ditemukan dari berbagai tempat.

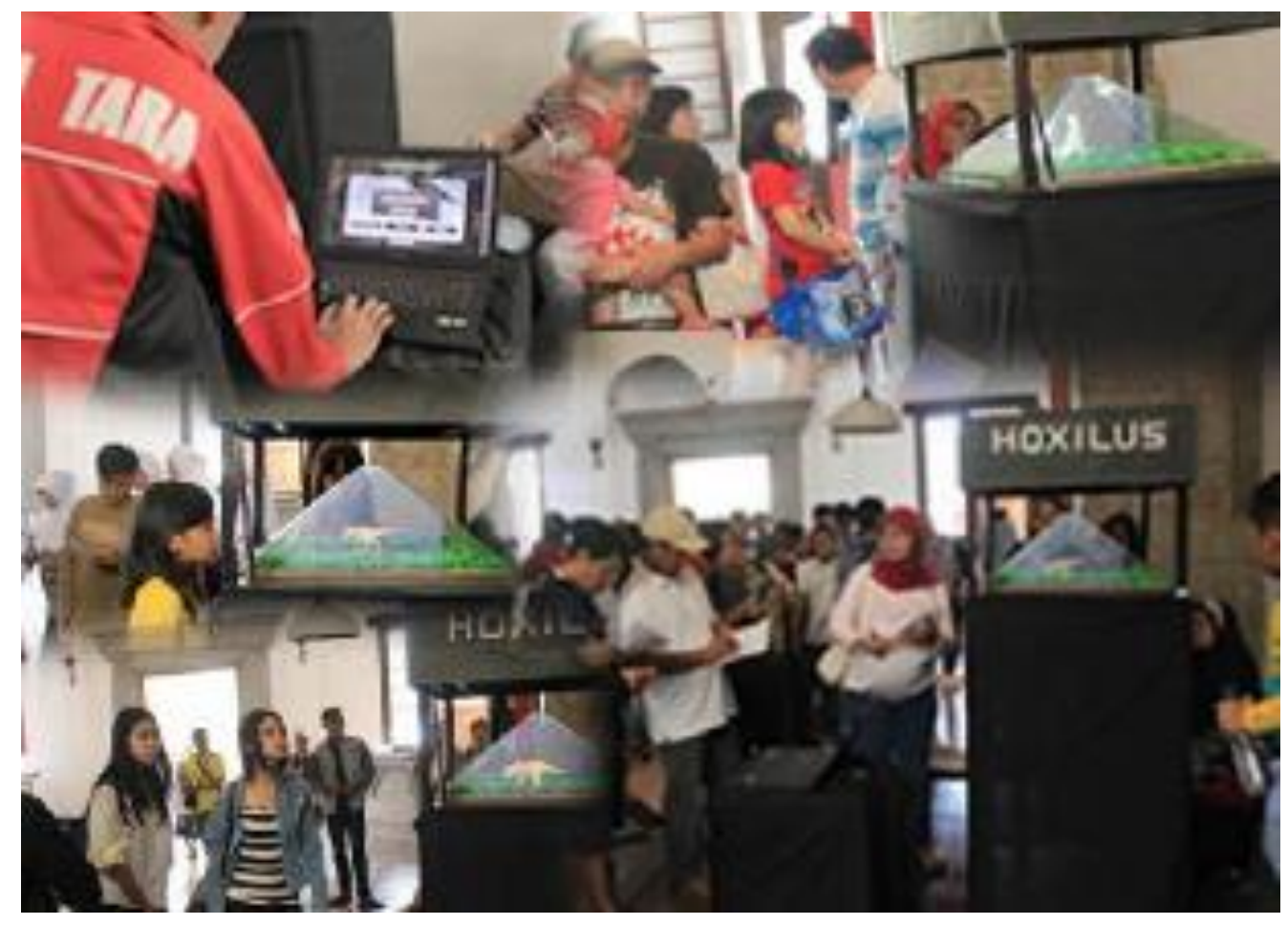

Gambar 12 Post test HOXILUS di Museum Geologi Bandung Sumber: Rustaman, 2018

\section{KESIMPULAN}

Berdasarkan penelitian dan perancangan yang telah dilakukan maka dapat disimpulkan bahwa Perancangan Fosil Digital Dinosaurus dengan Pemanfaatan Teknologi Digital Holobox di Museum Geologi Bandung mampu memberikan pengalaman baru bagi pengunjung dalam memperoleh informasi tentang Fosil Disnosaurus karena ditampilkan dalam bentuk digital hologram secara 
dimensional dengan kesan visual yang interaktif dan dinamis. Pengunjung bisa lebih leluasa dalam mengeksplorasi informasi fosil secara tidak terbatas mengingat keterbatasan konten dan ruang pamer yang tersedia.

Perancangan ini merupakan prototype, konten yang ditampilkan difokuskan pada informasi fosil Dinosaurus Tyrex yang hidup di Zaman Kapur. Kedepannya diiharapkan adanya peneliti/designer lain dapat mengembangkan lebih lanjut konten-konten lain, tidak hanya fosil namun benda- benda bersejarah lain yang ada di Museum dapat dirancang dengan display digital Hologram.

Media ini belum mampu memberikan kontrol berupa interaksi konten yang dapat digerakkan oleh pengguna, oleh karenanya sangat cocok untuk diintegrasikan dengan teknologi tambahan leap motion. Leap motion merupakan sebuah teknologi yang memiliki sensor untuk menangkap gerakan tangan, sehingga dalam penerapannya pengguna dapat mengontrol atau menggerakkan konten hologram dengan menggunakan gerakan tangan. Hal ini sangat berpotensi sekali untuk pengembangan design di masa yang akan datang. 


\section{DAFTAR PUSTAKA}

Ayo Kita Mengenal Museum 2009, Direktorat Museum, Jakarta.

Cromer, A. H. 1994, Fisika Untuk Ilmu-ilmu Hayati, Yogyakarta, Gadjah Mada University Press.

Elmorshidy, A 2010, 'Holographic Projection Technology: The World is Changing.', Jurnal of Telecommunications, vol. 2, no. 2, pp. 104-112, Diakses 10 February 2018, <https://arxiv.org/ftp/arxiv/papers/1006/1006.0846.pdf>

Fidler, R. 2003, Media Morfosis Memahami Media Baru, Jogjakarta, Bintang Budaya.

Green, T. D. dan Brown, A. 2002, Multimedia Project in the Clasroom, United States of America, Corwin Press, Inc.

Krauss, L. M., 3 (ed.), Fisika Star Trek, 2003, Jakarta, KPG (Kepustakaan Populer Gramedia).

Lefebvre, Henry dalam Hubbart, Phil dan Kitchin, R. 2011, Key Thinkers On Space, Sage Publication.

Nasrullah, R. 2012, Komunikasi Antarbudaya Di Era Budaya Siber, Jakarta, Kencana.

Novan, R. dan Triani, A. R. 2016, ‘Perancangan Buku Cerita Sejarah Ciung Wanara Berbasis Augmented Reality untuk Anak Sekolah Dasar', vol. 1, no.2, pp. 97115, Diakses 10 February 2018, <http://journals.telkomuniversity.ac.id/ demandia/article/view/275/180275-1-626-1-10-20161218.pdf.>

Palmer, dan Douglas, 2002, Buku saku: Fosil, Jakarta, Erlangga.

Setiawan, 1990, 10 (ed.), Ensiklopedia Nasional Indonesia No. 10 MYRDA, PT. Cipta Adi Pustaka.

Shadily, Hassan. dan Echols, John. M. 1982. Kamus Inggris. Jakarta: Gramedia 